\title{
Synergic Effect of Genistein and Daidzein on UVB-Induced DNA Damage: An Effective Photoprotective Combination
}

\author{
Barbara Iovine, ${ }^{1,2}$ Maria Luigia Iannella, ${ }^{1}$ Franco Gasparri, ${ }^{3}$ Giuseppe Monfrecola, ${ }^{4}$ \\ and Maria Assunta Bevilacqua ${ }^{1,2,5}$ \\ ${ }^{1}$ Dipartimento di Biochimica e Biotecnologie Mediche, Università degli Studi di Napoli "Federico II”, Via S. Pansini 5,
80131 Napoli, Italy
${ }^{2}$ CEINGE-Biotecnologie Avanzate, Via Comunale Margherita 482, 80145 Napoli, Italy
${ }^{3}$ Rottapharm-Madaus Dermo-Cosmetic Rß̊D Division, Via Valosa di Sopra 9, 20052 Monza, Italy
${ }^{4}$ Dipartimento di Patologia Sistematica, Sezione di Dermatologia, Facoltà di Medicina e Chirurgia,
Università degli Studi di Napoli “Federico II”, Via S. Pansini 5, 80131 Napoli, Italy
${ }^{5}$ Facoltà di Scienze Biotecnologiche, Università degli Studi di Napoli “Federico II”, Via S. Pansini 5, 80131 Napoli, Italy
}

Correspondence should be addressed to Maria Assunta Bevilacqua, mabevil@unina.it

Received 10 January 2011; Revised 11 March 2011; Accepted 19 May 2011

Academic Editor: Susan A. Rotenberg

Copyright (๑) 2011 Barbara Iovine et al. This is an open access article distributed under the Creative Commons Attribution License, which permits unrestricted use, distribution, and reproduction in any medium, provided the original work is properly cited.

\begin{abstract}
The anti-inflammatory effects and antioxidant activities of individual isoflavones are well established although little is known about the photoprotective effect of their combination. The aim of this study was to investigate the photoprotective effects of different concentrations of genistein and daidzein individually or combined. We measured the expression levels of the cyclo-oxygenase-2 (COX-2) and growth arrest and DNA-damage inducible (Gadd45) genes, which are involved in inflammation and DNA repair, respectively, in BJ-5ta human skin fibroblasts irradiated with $60 \mathrm{~mJ} / \mathrm{cm}^{2} \mathrm{UVB}$. We also determined the cellular response to UVBinduced DNA damage by Comet assay. We report that genistein and daidzein when administered combined, and at a specific concentration and ratio, exerted a synergistic photoprotective effect that was greater than the effect obtained with each isoflavone alone. The results reported herein suggest that low concentrations of genistein and daidzein combined may be good candidate ingredients for protective agents against UV-induced photodamage.
\end{abstract}

\section{Introduction}

Exposure of the skin to ultraviolet (UV) radiation, particularly to the short ultraviolet, UVB component $(280-320 \mathrm{~nm})$, causes oxidative damage to skin, resulting in sunburn, photoaging, and skin cancer [1]. Topical application of antioxidants has long been known to protect skin from oxidative damage produced by UV radiation. In addition, a number of natural antioxidant ingredients also have antiinflammatory properties and can be used in the treatment of conditions associated with oxidative damage such as photoaging and perhaps even skin cancer $[2,3]$. Flavonoids are natural antioxidants and include the subclass of isoflavones [4]. The most potent isoflavones are genistein and daidzein [1]. Numerous studies have proven the effectiveness of genistein and daidzein in reducing the radical oxygen species involved in the skin aging process. These substances, in fact, can be used to protect the skin from oxidative stress induced by UVB radiation $[1,5]$.

Genistein ( $4^{\prime}, 5,7$-trihydroxyisoflavone) inhibits the production of certain cytokines and eicosanoid biosynthesis by inhibiting protein tyrosine kinase, which suggests that they can modulate the promotional stage of the inflammatory responses [6]. Genistein also reduces the inflammatory edematous reaction and suppresses contact hypersensitivity induced by moderate doses of solar UV irradiation [7]. In addition, applied before UV-exposure, genistein prevented the UV radiation-dependent expression of cyclooxygenase-2 (COX-2) in cultures of human keratinocytes, which suggests that it exerts anti-inflammatory activity $[8,9]$.

Similarly, topical application of genistein before UVB radiation dose-dependently reduced c-fos and c-jun expression in the mouse skin [10]. More recently, topical genistein 
treatment of mouse skin was found to protect against UVBinduced oxidative DNA damage [11], and to exert antioxidant and anticarcinogenic effects in the skin of hairless mice [12]. The other isoflavone, daidzein, is just as effective as genistein in protecting cells against oxidative DNA damage [13].

In the pharmaceutical industry and particularly in the cosmetic industry, there is a demand for new substances or combinations of substances originating from natural resources endowed with antioxidant and cytophotoprotective activity. In the attempt to identify new effective photoprotective agents, we investigated the effects of the isoflavones genistein $(2-60 \mu \mathrm{M})$ and daidzein (8$30 \mu \mathrm{M})$ individually or combined in a $1: 4$ ratio, in BJ-5ta human skin cells irradiated with $60 \mathrm{~mJ} / \mathrm{cm}^{2}$ UVB. Antiinflammatory and DNA repair properties were assessed by measuring cell viability and the expression of the cyclooxygenase-2 (COX-2) and growth arrest DNA damageinducible (Gadd45) genes that are involved in inflammation and DNA repair, respectively. Finally, the UVBinduced DNA damage in cells was evaluated by single-cell gel electrophoresis assay (Comet assay). We demonstrate that the isoflavones genistein and daidzein combined at a specific ratio exert a greater photoprotective effect than each isoflavone alone. Consequently, this genistein/daidzein combination has promising applications in the protection of skin cells against UVB irradiation.

\section{Materials And Methods}

2.1. Cell Culture. BJ-5ta cells, which are human skin fibroblast cells immortalized with hTERT, were cultured in a 4:1 mixture of Dulbecco's medium (Gibco Laboratories, North Andover, Mass, USA) and Medium 199 (SigmaAldrich, Oakville, ON, Canada) supplemented with: 4 parts of Dulbecco's Modified Eagle's Medium (DMEM) (Gibco Laboratories) containing $4 \mathrm{mM}$ L-glutamine (Gibco Laboratories), $4.5 \mathrm{~g} / \mathrm{L}$ glucose and $1.5 \mathrm{~g} / \mathrm{L}$ sodium bicarbonate, 1 part of Medium 199 (Sigma), in turn, supplemented with: $0.01 \mathrm{mg} / \mathrm{mL}$ hygromycin B (Sigma), 10\% fetal bovine serum (FBS) (Gibco Laboratories), 1\% penicillin/streptomycin (Gibco Laboratories). Cultures were maintained at $37^{\circ} \mathrm{C}$ in a $5 \% \mathrm{CO}_{2}$-humidified atmosphere.

2.2. Treatment with Genistein and Daidzein. BJ-5ta were plated onto $60-\mathrm{mm}$ culture plates in $4 \mathrm{~mL}$ of fresh culture medium. After incubation for 1 day at $37^{\circ} \mathrm{C}$ in $5 \% \mathrm{CO}_{2}$, genistein (dissolved in ethanol) and/or daidzein (dissolved in DMSO) were added to the culture medium and BJ-5ta cells were incubated for $2 \mathrm{~h}$ at $37^{\circ} \mathrm{C}$ prior to UVB irradiation at $60 \mathrm{~mJ} / \mathrm{cm}^{2}$. Twenty-four hours after UV irradiation, cells were washed with PBS, total RNA was prepared from BJ-5ta cells and DNA damage was evaluated with the Comet assay. Genistein was purchased from Nutraceutica Srl (Monterenzio, Italy) and daidzein was obtained from Cayman Chemical Company (Ann Arbor, Mish, USA).

2.3. UV Irradiation. BJ-5ta fibroblasts were seeded onto $60-\mathrm{mm}$ culture plates in $4 \mathrm{~mL}$ of fresh culture medium.
After incubation for 1 day at $37^{\circ} \mathrm{C}$ in $5 \% \mathrm{CO}_{2}$, cells were washed and covered with phosphate-buffered saline (PBS) with $0.5 \mathrm{~mL}$ of cold PBS, and the monolayer of subconfluent cells was irradiated with UVB $(290-320 \mathrm{~nm})$. The PBS was then replaced with $4 \mathrm{~mL}$ of culture medium containing the isoflavones, and the cells were allowed to recover for $24 \mathrm{~h}$. As a source of UVB, six Philips TL12/60W fluorescent lamps (Philips, Eindhoven, The Netherlands) emitting UV light between 290 and $320 \mathrm{~nm}$ with a peak at $300 \mathrm{~nm}$ was used. The intensity of UVB irradiation, measured with a UV meter (Spectrolyne mod., Spectronics Corp., Westbury, NY, USA) was $0.8 \mathrm{~mW} / \mathrm{cm}^{2}$.

2.4. Analysis of Cell Viability. Cell vitality was determined with the Trypan blue method. Twenty-four hours after irradiation or after treatment with isoflavones, the medium was recovered and cells were washed twice with PBS and incubated with trypsin/EDTA. Cells were then harvested with medium previously recovered and centrifuged at $1000 \times \mathrm{g}$ for $10 \mathrm{~min}$. The cell pellet was resuspended in an appropriate volume of PBS, and $0.5 \mathrm{~mL}$ of the cell suspension was combined with $0.5 \mathrm{~mL}$ of Trypan blue solution. The mix was incubated for $15 \mathrm{~min}$ at room temperature and the number of unstained cells (vital cells) and the total number of cells (vital and not) were determined on the hemacytometer under a microscope (dead cells will take up the Trypan blue stain). The percentage of viable cells was determined dividing the number of unstained cells by the total number of cells.

2.5. RNA Extraction and Real-Time PCR. BJ-5ta cells were exposed to UVB or treated with isoflavones for $2 \mathrm{~h}$ before UVB irradiation and harvested after $24 \mathrm{~h}$ for RNA extraction. Total RNA was prepared with the RNeasy mini kit (Qiagen) and subjected to cDNA synthesis with random hexanucleotide primers and MultiScribe reverse transcriptase (Invitrogen) at $48^{\circ} \mathrm{C}$ for $1 \mathrm{~h}$. The cDNA was then amplified in an iCycler iQ real time PCR detection system (Bio-Rad Laboratories) using iQTM SYBR Green Supermix (Bio-Rad Laboratories) in triplicate in $25 \mu \mathrm{L}$ reaction volumes. Relative quantification of gene expression was performed using the $2^{-\Delta \Delta \mathrm{Ct}}$ method. Actin served as reference mRNA [14]. The ratios between $2^{-\Delta \Delta \mathrm{Ct}}$ before UVB treatment and those calculated for the samples exposed to UVB light are expressed as fold changes. The primer sequences were as follows:

Gadd45 forward: 5' -AGACCCCGGACCTGCACT-3' Gadd45 reverse: 5'-CCGGCAAAAACAAATAAGTTGACT-3'

COX-2 forward: 5'-CCTGGCGCTCAGCCATAC-3'

COX-2 reverse: 5'-GGTACAATCGCACTTATACTGGTCAA-3'

actin forward: $5^{\prime}$-CCTCACCCTGAAGTACCCCA-3' actin reverse: $5^{\prime}$-TCGTCCCAGTTGGTGACGAT-3'

2.6. Comet Assay. DNA damage was evaluated with the Comet assay as previously described [15]. Briefly, the cells were exposed to UVB or treated with isoflavones $2 \mathrm{~h}$ 


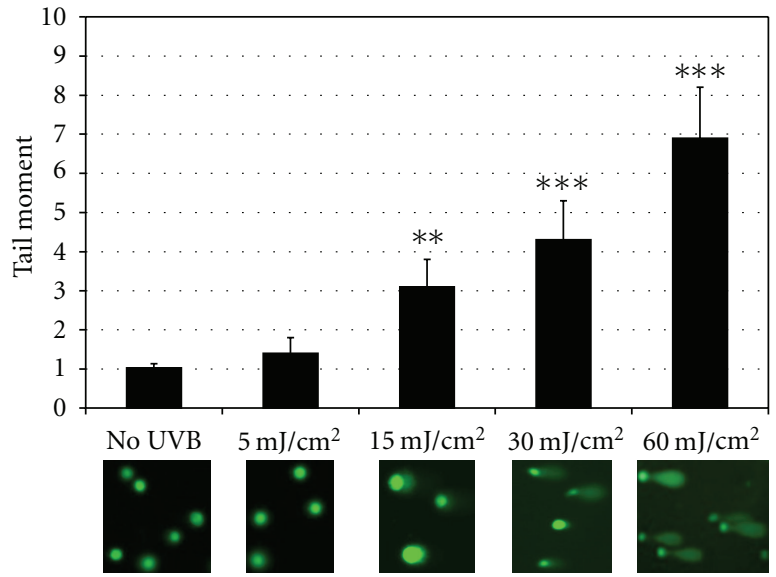

(a)

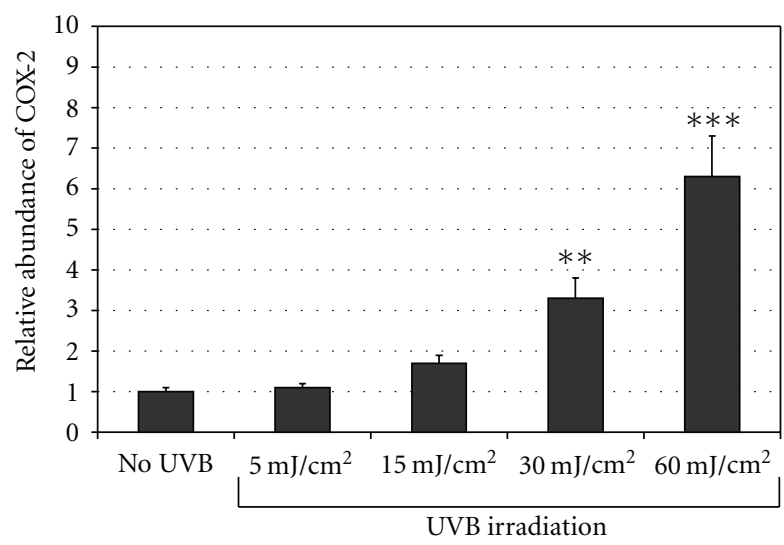

(c)

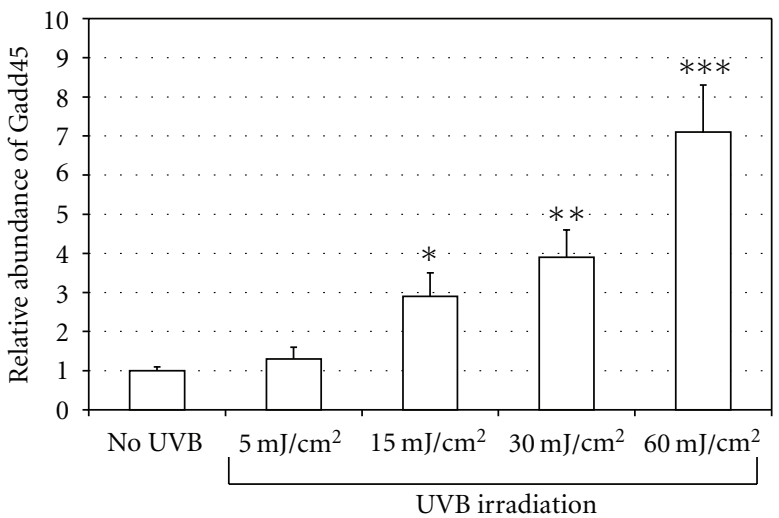

(b)

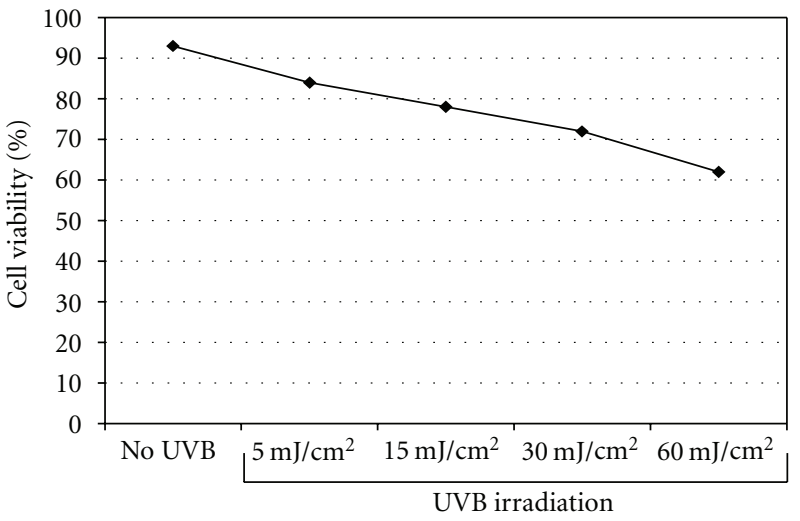

(d)

FIGURE 1: Effects of UVB irradiation on DNA damage and cell viability. (a) BJ-5ta cells were grown as described under Section 2, exposed to increasing doses of UVB irradiation (from 5 to $60 \mathrm{~mJ} / \mathrm{cm}^{2}$ ) and harvested $24 \mathrm{~h}$ after UVB. The Comet assay (see Section 2) was performed according to the manufacturer's instructions. The results were quantified using the NIH Image Software. The data are reported as tail moment $(\mathrm{TM})$ and represent the mean $\pm \mathrm{SD}$ of three independent experiments. ${ }^{* *} P<0.001$, ${ }^{* * *} P<0.0001$ (Ctrl: unirradiated control cells). (b, c) Gadd45 and COX-2 mRNA were measured by real time-PCR in a total RNA preparation from exponentially growing human fibroblasts (BJ-5ta) $24 \mathrm{~h}$ after UVB irradiation (from 5 to $60 \mathrm{~mJ} / \mathrm{cm}^{2}$ ). The bars indicate the relative abundance of the mRNA; +1 is the abundance of Gadd45 and COX-2 mRNA in unirradiated cells. All values represent the mean \pm SD of triplicate experiments. ${ }^{*} P<0.05$, ${ }^{* *} P<0.001,{ }^{* *} P<0.0001$. (d) The viability of BJ-5ta was measured by Trypan blue $24 \mathrm{~h}$ after UVB irradiation at increasing doses. The results are reported as percentage of cell viability and the values represent the mean values \pm SD of three independent experiments (Ctrl: unirradiated control cells).

before UVB irradiation, as described above, and $24 \mathrm{~h}$ later, they were washed with PBS, trypsinized, resuspended in PBS and combined with LM-agarose (supplied with the Trevigen kit; Trevigen Inc., Gaithersburg, Md) at a ratio of $1: 8$ (cells: agarose). Electrophoretic and qualitative and/or quantitative analyses were carried out according to the Trevigen protocol. The results were quantified with the Image software, as suggested by the manufacturer. Data are reported as tail moment (TM), which is the ratio between the tail and nucleus areas.

2.7. Statistics. Results were expressed as the mean $\pm \mathrm{SE}$ of 3 experiments. Statistical significance was calculated by one-way analysis of variance (ANOVA) and $P$ value for a multiple comparison test. The level of statistical significance was defined as ${ }^{*} P<0.05,{ }^{* *} P<0.001$, ${ }^{* * *} P<0.0001$.

\section{Results}

3.1. COX-2 and Gadd45 Gene Expression and DNA Damage in UVB-Irradiated Cells. We used the alkaline Comet assay to evaluate the damage caused to DNA from proliferating BJ-5ta fibroblasts irradiated with increasing doses of UVB (from 5 to $60 \mathrm{~mJ} / \mathrm{cm}^{2}$ ) [15]. As shown in Figure 1(a), in UVB-irradiated cells the TM (tail moment) of comets increased as the dose of UVB irradiation increased. These results are in agreement with the level of the Gadd 45 mRNA measured by real-time PCR (Figure 1(b)). Transcription of this gene is rapidly induced upon DNA damage [16]. To evaluate the effect of UVB irradiation on COX-2 gene expression, we measured its mRNA levels in proliferating BJ-5ta fibroblasts irradiated with increasing doses of UVB (from 5 to $60 \mathrm{~mJ} / \mathrm{cm}^{2}$ ). As shown in Figure 1(c), COX-2 mRNA 


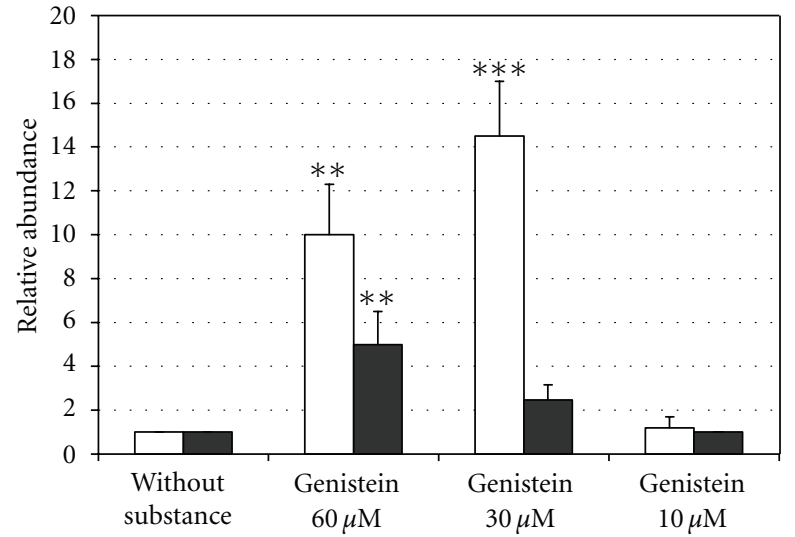

$\square$ Gadd45

$\square$ COX-2

(a)

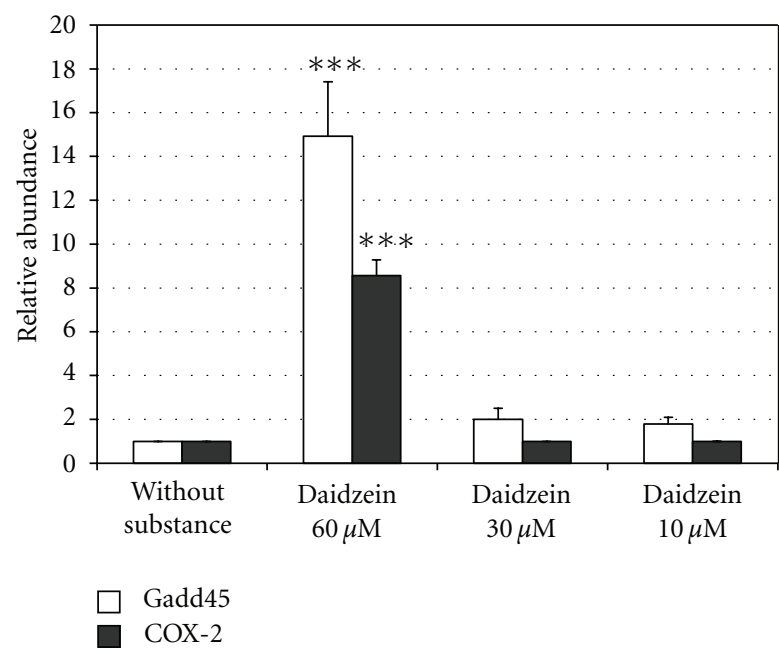

(c)

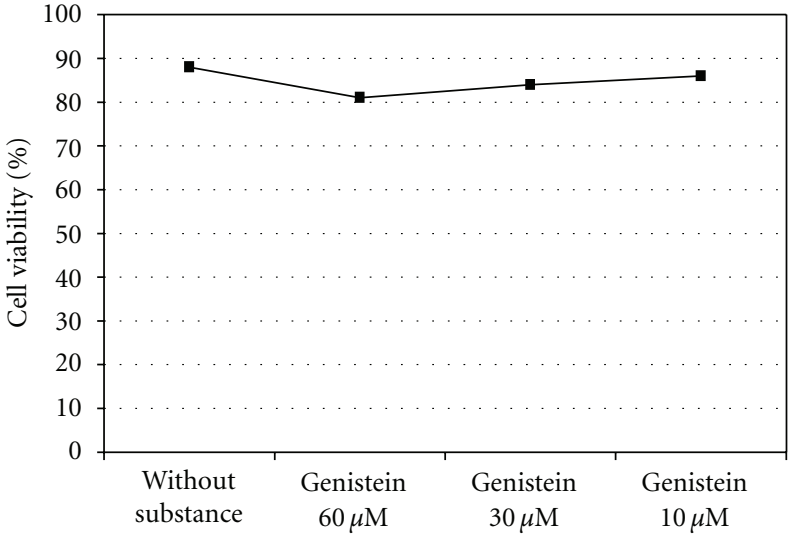

(b)

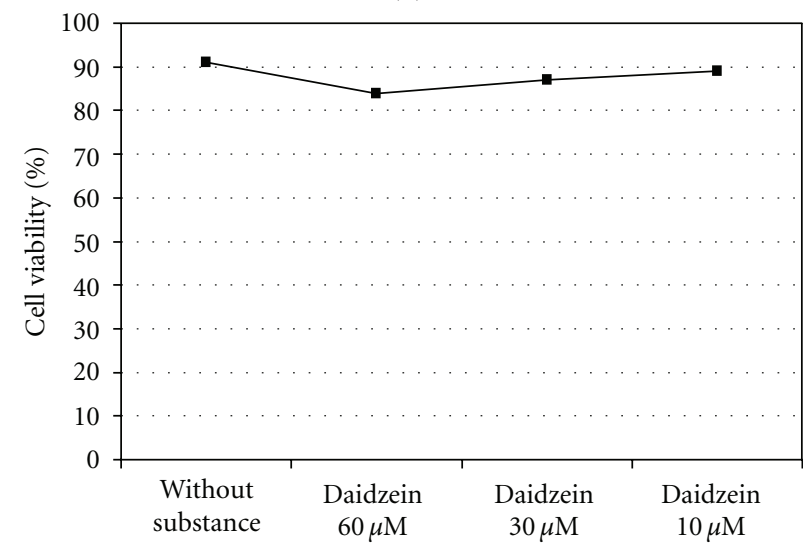

(d)

FIGURE 2: Effects of genistein and daidzein on Gadd45 and COX-2 mRNA levels and on BJ-5ta cell viability. (a, c) mRNA levels of Gadd45 and COX-2 were determined by real-time PCR in a total RNA preparation of BJ-5ta cells treated with various concentrations of genistein (from 10 to $60 \mu \mathrm{M}$ ) (a) or daidzein (from 10 to $60 \mu \mathrm{M}$ ) (c) for $24 \mathrm{~h}$. The bars indicate the relative abundance of the mRNA; +1 is the abundance of Gadd45 and COX-2 mRNA in untreated cells. All values represent the mean \pm SD of triplicate experiments. ${ }^{* *} P<0.001,{ }^{* * *} P<0.0001$ (Ctrl: untreated control cells). (b, d) Cell viability was measured by Trypan blue in BJ-5ta cells incubated with genistein (from 10 to $60 \mu \mathrm{M}$ ) or daidzein (from 10 to $60 \mu \mathrm{M}$ ) for $24 \mathrm{~h}$. The results are reported as percentage of cell viability, and the values represent the mean values \pm SD of three independent experiments (Ctrl: untreated control cells).

levels increased as the dose of UVB irradiation increased. The effects of UVB irradiation on cell viability are depicted in Figure 1(d). There was a dose-dependent decrease in cell viability; however, $60 \%$ of cells were still viable at $60 \mathrm{~mJ} / \mathrm{cm}^{2}$.

\subsection{Effects of Genistein and Daidzein on COX-2 and Gadd45} Gene Expression in Unirradiated Cells. To determine whether genistein and daidzein affected the expression levels of the COX-2 and Gadd45 genes, we first examined their effects on gene expression in non-UVB irradiated BJ-5ta skin cells. Figures 2(a) and 2(c) show the mRNA levels of COX-2 and Gadd45, determined by real time-PCR, after exposure to various concentrations of genistein and daidzein $(10,30$, $60 \mu \mathrm{M})$, respectively, in non-UVB irradiated BJ-5ta skin cells. The expression of the COX-2 and Gadd45 genes was not affected by a concentration of $10 \mu \mathrm{M}$ genistein or $30 \mu \mathrm{M}$ daidzein. Instead, exposure to a concentration of $30 \mu \mathrm{M}$ genistein or $60 \mu \mathrm{M}$ daidzein resulted in an increase of COX2 and Gadd45 mRNA levels. This effect was much more evident for Gadd 45 than for COX-2. Indeed, $30 \mu \mathrm{M}$ genistein did not significantly induce COX-2 gene expression. DMSO or ethanol used as a vehicle control in cells in the absence of isoflavones did not affect Gadd45 and COX-2 expression (data not shown). The isoflavones at the concentrations tested did not affect cell viability (Figures 2(b) and 2(d)).

3.3. Response to UVB-Irradiated Cells Treated with Low and High Concentrations of Genistein and Daidzein Used Singly or in Combination. To test the effect of genistein and daidzein on COX-2 and Gadd45 gene expression in BJ-5ta human 


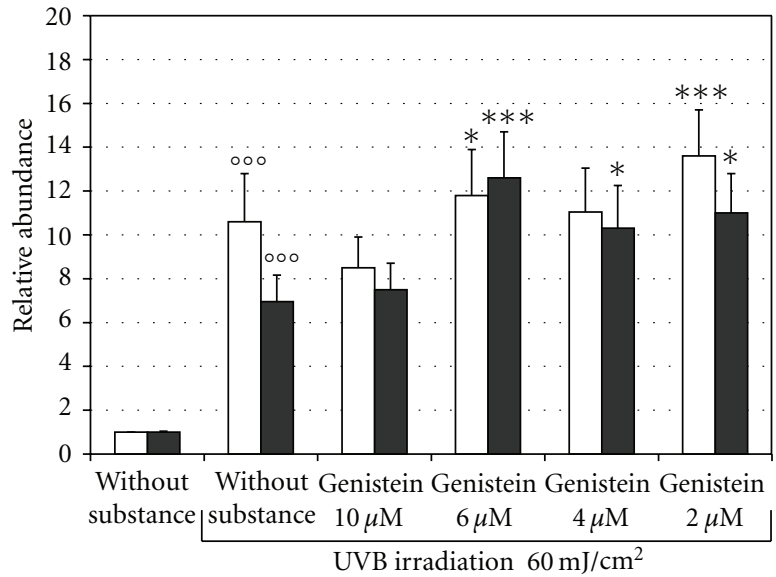

Gadd45

COX-2

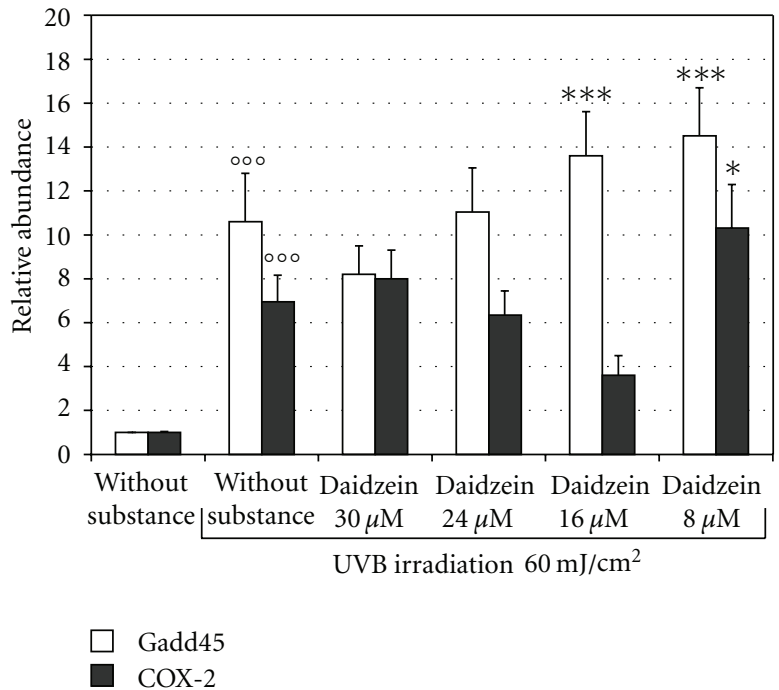

(b)

(a)

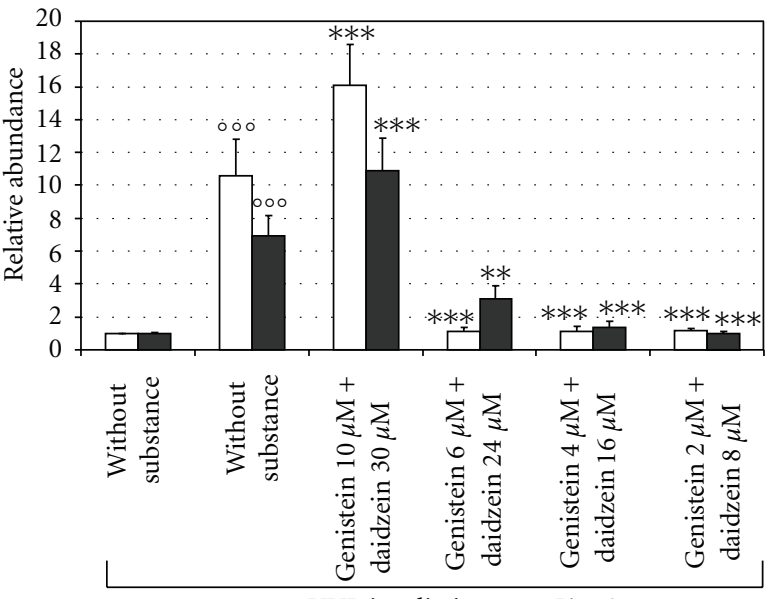

UVB irradiation $60 \mathrm{~mJ} / \mathrm{cm}^{2}$

Gadd45

COX-2

(c)

FIGURE 3: Effects of genistein and daidzein on Gadd45 and COX-2 gene expression in BJ-5ta cells irradiated with $60 \mathrm{~mJ} / \mathrm{cm}^{2} \mathrm{UVB}$. $\mathrm{mRNA}$ levels of Gadd45 and COX-2 were determined by Real Time-PCR in BJ-5ta cells treated for $2 \mathrm{~h}$ with various concentrations of genistein (from 2 to $10 \mu \mathrm{M}$ ) (a) or daidzein (from 8 to $30 \mu \mathrm{M}$ ) (b) or with different combinations of genistein and daidzein (c) before UVB irradiation $\left(60 \mathrm{~mJ} / \mathrm{cm}^{2}\right)$ and harvested $24 \mathrm{~h}$ after UVB. The bars indicate the relative abundance of the mRNA; +1 is the abundance of Gadd 45 and COX-2 mRNA in unirradiated and untreated cells. All values represent the mean \pm SD of triplicate experiments. ${ }^{*} P<0.05, * * P<0.001$, ${ }^{* * *} P<0.0001,{ }^{\circ 00} P<0.0001$ (Ctrl: untreated and unirradiated control cells; without substance: untreated and irradiated $\left(60 \mathrm{~mJ} / \mathrm{cm}^{2}\right) \mathrm{cells}$ ).

skin cells irradiated with $60 \mathrm{~mJ} / \mathrm{cm}^{2} \mathrm{UVB}$, we used the concentration of each isoflavone that did not induce gene expression, namely $10 \mu \mathrm{M}$ genistein and $30 \mu \mathrm{M}$ daidzein. Figures 3(a) and 3(b) show the mRNA levels of COX-2 and Gadd45, determined by Real Time-PCR, in BJ-5ta cells treated with various concentrations of genistein (from 2 to $10 \mu \mathrm{M}$ ) and daidzein (from 8 to $30 \mu \mathrm{M}$ ) respectively, $2 \mathrm{~h}$ before irradiation with $60 \mathrm{~mJ} / \mathrm{cm}^{2}$ UVB. The isoflavones used singly or in combination at concentrations of $10 \mu \mathrm{M}$ genistein and $30 \mu \mathrm{M}$ daidzein did not modify significantly the levels of the Gadd45 and COX-2 genes (Figures 3(a), 3(b) and $3(\mathrm{c})$ ). On the contrary, as shown in Figure 3(c), COX-2 and Gadd45 expression levels were significantly reduced $(P<$ 0.0001 ) when the isoflavones were used in combination at lower concentrations $(2,4$ and $6 \mu \mathrm{M}$ genistein, and 8,16 , and $24 \mu \mathrm{M}$ daidzein) that is, at a ratio of $1: 4$. DMSO and 


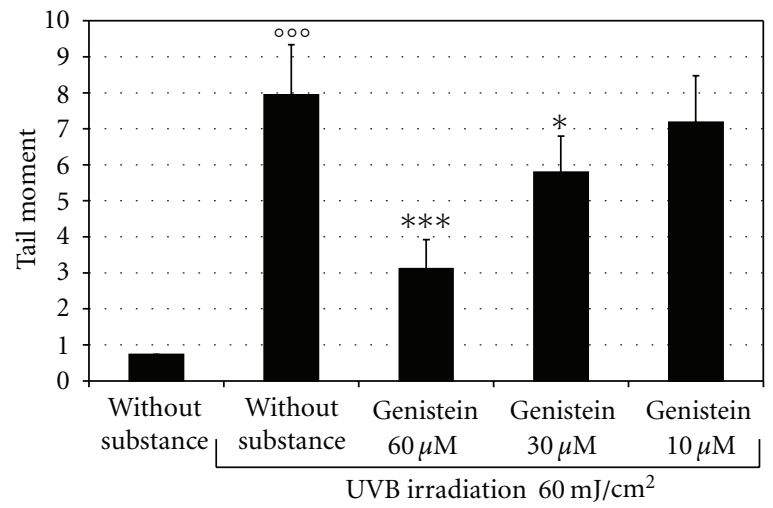

(a)

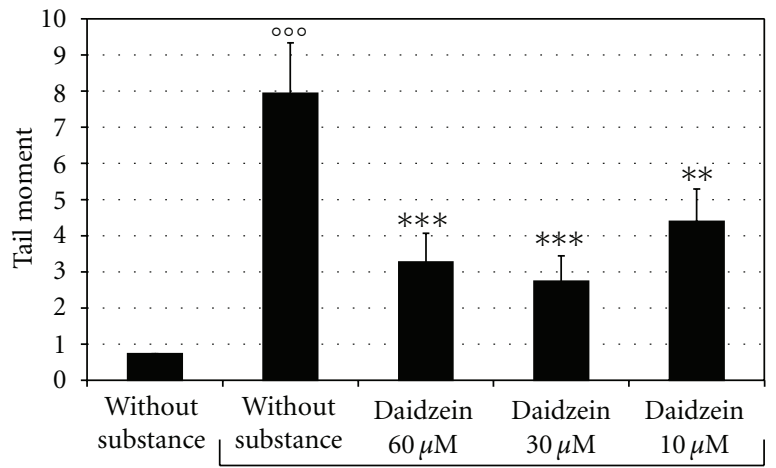

UVB irradiation $60 \mathrm{~mJ} / \mathrm{cm}^{2}$

(b)

Figure 4: Photoprotective effect of isoflavones evaluated with the Comet assay. (a) BJ-5ta cells were treated for $2 \mathrm{~h}$ with various concentrations of genistein (from 10 to $60 \mu \mathrm{M}$ ). (b) BJ-5ta cells were treated for $2 \mathrm{~h}$ with various concentrations of daidzein (from 10 to $60 \mu \mathrm{M}$ ).

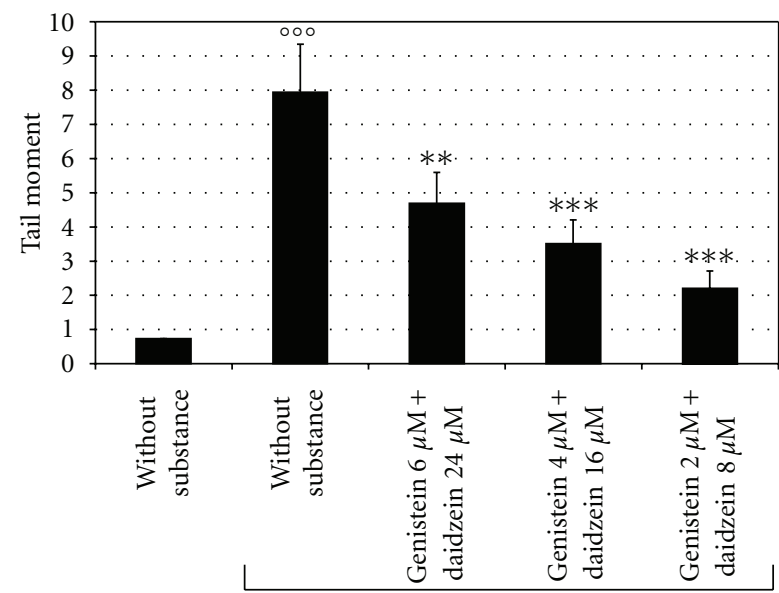

UVB irradiation $60 \mathrm{~mJ} / \mathrm{cm}^{2}$

(a)

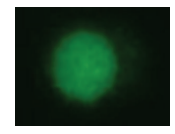

Without substance

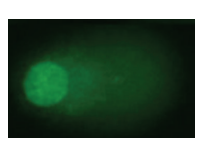

Without substance

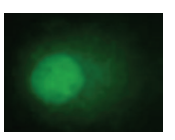

Genistein
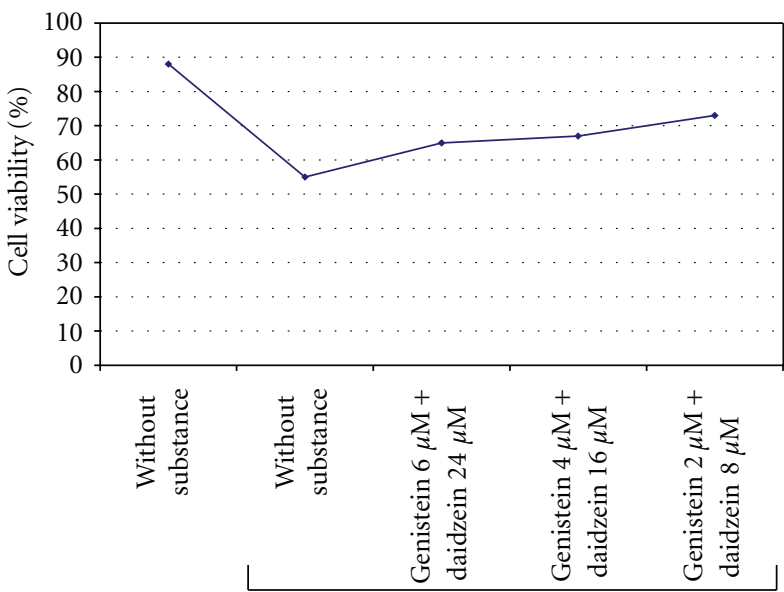

UVB irradiation $60 \mathrm{~mJ} / \mathrm{cm}^{2}$

(b)

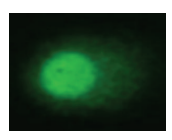

Daidzein

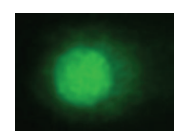

Genistein $2 \mu \mathrm{M}+$ daidzein $8 \mu \mathrm{M}$

UVB irradiation $60 \mathrm{~mJ} / \mathrm{cm}^{2}$

(c)

Figure 5: Photoprotective effect of genistein and daidzein in combination evaluated with the Comet assay. (a) BJ-5ta cells were treated for $2 \mathrm{~h}$ with different combination of genistein and daidzein before UVB irradiation $\left(60 \mathrm{~mJ} / \mathrm{cm}^{2}\right)$ and harvested $24 \mathrm{~h}$ after UVB. The Comet assay procedure (see Section 2) was performed according to the manufacturer's instructions. The results were quantified using the NIH Image Software. The data are reported as Tail Moment (TM) and represent the mean $\pm \mathrm{SD}$ of three independent experiments. ${ }^{*} P<0.05$, ${ }^{* *} P<0.001,{ }^{* * *} P<0.0001,{ }^{000} P<0.0001$ (Ctrl: untreated and unirradiated control cells; without substance: untreated and irradiated $\left(60 \mathrm{~mJ} / \mathrm{cm}^{2}\right)$ cells). (b) Cell viability was measured by Trypan blue in BJ-5ta cells incubated with genistein and daidzein in combination for $24 \mathrm{~h}$ (genistein $6 \mu \mathrm{M}+$ daidzein $24 \mu \mathrm{M}$, genistein $4 \mu \mathrm{M}+$ daidzein $16 \mu \mathrm{M}$, genistein $2 \mu \mathrm{M}+$ daidzein $8 \mu \mathrm{M}$ ). The results are reported as percentage of cell viability and the values represent the mean values $\pm \mathrm{SD}$ of three independent experiments (Ctrl: untreated control cells). (c) Image of alkaline single-cell gel electrophoresis performed on BJ-5ta treated with genistein or daidzein alone or in their most effective combination (Ctrl: untreated and unirradiated control cells; without substance: untreated cells with severe DNA damage after irradiation with $60 \mathrm{~mJ} / \mathrm{cm}^{2} \mathrm{UVB}$ ). 
ethanol in combination used as a vehicle control in nonUVB-irradiated BJ-5ta skin cells without isoflavones did not affect Gadd45 and COX-2 expression (data not shown).

3.4. Photoprotective Effect of Genistein and Daidzein on the Cellular Response to UVB-Induced DNA Damage. We evaluated the cellular response to UVB-induced DNA damage using the Comet assay [15]. First, we assessed the effects of various concentrations of each isoflavone (from 10 to $60 \mu \mathrm{M}$ ) on UVB-induced DNA damage evaluated as TM. As shown in Figures 4(a) and 4(b), $60 \mu \mathrm{M}$ genistein or $30 \mu \mathrm{M}$ daidzein, administered $2 \mathrm{~h}$ before irradiation with $60 \mathrm{~mJ} / \mathrm{cm}^{2} \mathrm{UVB}$, prevented the UVB-induced DNA damage by about $65 \%$ and $70 \%$, respectively. Instead, the isoflavone combinations used at concentrations of 2,4 , and $6 \mu \mathrm{M}$ genistein in the presence of 8,16 and $24 \mu \mathrm{M}$ daidzein, respectively, more effectively prevented UVB-induced DNA damage (Figure 5(a)). The isoflavones combination also improved the viability of UVB irradiated cells (Figure 5(b)). Figure 5(c) shows the results of the Comet assays at the most effective concentrations of genistein and daidzein used singly or in combination.

\section{Discussion}

The aim of this study was to investigate the efficacy of two isoflavones, genistein and daidzein, used individually or combined, in protecting against the inflammation and DNA damage induced by UVB irradiation. The anti-inflammatory effects and antioxidant activities of individual isoflavones are well established although little is known about the photoprotective effect of their combination. First, we investigated the effect of the two isoflavones on the UVB-induced expression of the COX-2 and Gadd45 genes. In fact, UV radiation induces COX-2 expression, which results in cell aging and skin carcinogenesis [16]. In addition, stressful conditions such as ionizing radiation induce the expression of the Gadd45 gene, which is involved in cellular repair [17]. The Gadd45 protein is a stress sensor and its function is mediated by a complex interplay of physical interactions with other cellular proteins that are implicated in cell-cycle arrest, DNA repair and cell survival, or apoptosis. How the stress sensor functions of the Gadd45 protein coordinate the response of cells to environmental and physiological stressors is unclear [18].

We evaluated the expression levels of the COX-2 and Gadd45 genes in unirradiated and UVB $60 \mathrm{~mJ} / \mathrm{cm}^{2}$ irradiated human skin BJ-5ta cells exposed to each isoflavone alone or their combination. We found that, used alone, $30 \mu \mathrm{M}$ genistein and $60 \mu \mathrm{M}$ daidzein reduced the UVBinduced DNA damage but not the expression of the COX-2 and Gadd45 genes. Instead, lower concentrations of genistein and daidzein applied together exerted significant antiinflammatory effects and promoted DNA repair. Indeed, under the latter condition, we found a reduction of cellular DNA damage measured by the Comet assay. This study reveals that (i) genistein and daidzein exerted a synergistic photoprotective effect that was greater than the effect obtained with each isoflavone alone and (ii) the isoflavone ratio is critical for the cytoprotective effect.
Our results are consistent with recent studies on the effects exerted by genistein and other isoflavones in a number of cellular systems. Genistein alone or combined with capsaicin was found to exert anti-inflammatory and anticarcinogenic effects by modulating COX-2 in a mammary cancer cell line [19]. In vivo studies showed that the topical application of isoflavone extract, before UVB irradiation, reduced the expressions of COX-2 and of the proliferating cell nuclear antigen [20]. Moreover, soy extract in vitro reduced the UV-induced expression of COX-2, which suggests that it exerts anti-inflammatory activity, and inhibits angiogenesis and tumor progression [20, 21]. In our study, the two isoflavones, also individually, were photoprotective at the highest concentrations used $(60 \mu \mathrm{M}$ genistein and $30 \mu \mathrm{M}$ daidzein) when the UVB-induced DNA damage was assessed by Comet assay. Other authors reported that high doses of genistein (10-50 $\mu \mathrm{M}, 1 \mathrm{~h}$ before UV irradiation) prevented UV-induced DNA pyrimidine dimmer formation in reconstituted 3D cultured human skin models [22].

\section{Conclusion}

The results reported herein suggest that isoflavones, besides contributing to activation of DNA repair mechanisms, may also function as anti-inflammatory agents in skin cells exposed to UVB irradiation. Indeed, cells respond to isoflavones by inducing Gadd45 gene expression thereby activating the DNA repair system, and also by reducing the COX-2 expression, thereby exerting significant antiinflammatory effects. Our findings show that genistein and daidzein, when administered combined and at a specific concentration and ratio, exert a synergistic photoprotective effect that is greater than the effect obtained with each isoflavone alone. Consequently, genistein and daidzein may be good candidate ingredients for protective agents against UV-induced photodamage, and in particular, they may improve sunscreen protection.

\section{Conflict of Interests}

These authors disclose the following: Dr. Gasparri is an advisor for Rottapharm-Madaus. The remaining authors disclose no conflicts.

\section{Acknowledgment}

The authors are grateful to Jean Ann Gilder (Scientific Communication srl) for text editing.

\section{References}

[1] F. Afaq and H. Mukhtar, "Botanical antioxidants in the prevention of photocarcinogenesis and photoaging," Experimental Dermatology, vol. 15, no. 9, pp. 678-684, 2006.

[2] J. Fuchs, "Potentials and limitations of the natural antioxidants RRR-alpha-tocopherol, L-ascorbic acid and $\beta$-carotene in cutaneous photoprotection," Free Radical Biology and Medicine, vol. 25, no. 7, pp. 848-873, 1998.

[3] D. P. Steenvoorden and G. M. van Henegouwen, "The use of endogenous antioxidants to improve photoprotection," 
Journal of Photochemistry and Photobiology, vol. 41, no. 1, pp. 1-10, 1997.

[4] D. S. Berson, "Natural antioxidants," Journal of Drugs in Dermatology, vol. 7, supplement 7, pp. 7-12, 2008.

[5] Z. R. Huang, C. F. Hung, Y. K. Lin, and J. Y. Fang, "In vitro and in vivo evaluation of topical delivery and potential dermal use of soy isoflavones genistein and daidzein," International Journal of Pharmaceutics, vol. 364, no. 1, pp. 36-44, 2008.

[6] K. B. Glaser, A. Sung, J. Bauer, and B. M. Weichman, "Regulation of eicosanoid biosynthesis in the macrophage," Biochemical Pharmacology, vol. 45, no. 3, pp. 711-721, 1993.

[7] S. Widyarini, N. Spinks, A. J. Husband, and V. E. Reeve, "Isoflavonoid compounds from red clover (Trifolium pratense) protect from inflammation and immune suppression induced by UV radiation," Photochemistry and Photobiology, vol. 74, no. 3, pp. 465-470, 2001.

[8] K. Isoherranen, K. Punnonen, C. Jansen, and P. Uotilas, "Ultraviolet irradiation induces cyclooxygenase-2 expression in keratinocytes," British Journal of Dermatology, vol. 140, no. 6, pp. 1017-1022, 1999.

[9] S. Hooshmand, Y. Soung do, E. A. Lucas, S. V. Madihally, C. W. Levenson, and B. H. Arjmandi, "Genistein reduces the production of proinflammatory molecules in human chondrocytes," Journal of Nutritional Biochemistry, vol. 18, no. 9, pp. 609-614, 2007.

[10] Y. Wang, X. Zhang, M. Lebwohl, V. De Leo, and H. Wei, "Inhibition of ultraviolet B (UVB)-induced c-fos and c-jun expression in vivo by a tyrosine kinase inhibitor genistein," Carcinogenesis, vol. 19, no. 4, pp. 649-654, 1998.

[11] J. Y. Lin, J. A. Tournas, J. A. Burch, N. A. MonteiroRiviere, and J. Zielinski, "Topical isoflavones provide effective photoprotection to skin," Photodermatology Photoimmunology and Photomedicine, vol. 24, no. 2, pp. 61-66, 2008.

[12] K. Miyazaki, T. Hanamizu, R. Iizuka, and K. Chiba, "Genistein and daidzein stimulate hyaluronic acid production in transformed human keratinocyte culture and hairless mouse skin," Skin Pharmacology and Applied Skin Physiology, vol. 15, no. 3, pp. 175-183, 2002.

[13] P. Foti, D. Erba, P. Riso, A. Spadafranca, F. Criscuoli, and G. Testolin, "Comparison between daidzein and genistein antioxidant activity in primary and cancer lymphocytes," Archives of Biochemistry and Biophysics, vol. 15, no. 2, pp. 421427, 2005.

[14] M. A. Bevilacqua, B. Iovine, N. Zambrano et al., "Fibromodulin gene transcription is induced by ultraviolet irradiation, and its regulation is impaired in senescent human fibroblasts," Journal of Biological Chemistry, vol. 280, no. 36, pp. 3180931817, 2005.

[15] B. Iovine, M. Nino, C. Irace, M. A. Bevilacqua, and G. Monfrecola, "Ultraviolet B and A irradiation induces fibromodulin expression in human fibroblasts in vitro," Biochimie, vol. 91, no. 3, pp. 364-372, 2009.

[16] O. A. Belton, A. Duffy, S. Toomey, and D. J. Fitzgerald, "Cyclooxygenase isoforms and platelet vessel wall interactions in the apolipoprotein E knockout mouse model of atherosclerosis," Circulation, vol. 108, no. 24, pp. 3017-3023, 2003.

[17] D. A. Liebermann and B. Hoffman, "Gadd45 in the response of hematopoietic cells to genotoxic stress," Blood Cells, Molecules, and Diseases, vol. 39, no. 3, pp. 329-335, 2007.

[18] D. A. Liebermann and B. Hoffman, "Gadd45 in stress signaling," Journal of Molecular Signaling, vol. 3, pp. 15-23, 2008.

[19] J. T. Hwang, Y. K. Lee, J. I. Shin, and O. J. Park, "Antiinflammatory and anticarcinogenic effect of genistein alone or in combination with capsaicin in TPA-treated rat mammary glands or mammary cancer cell line," Annals of the New York Academy of Sciences, vol. 1171, pp. 415-420, 2009.

[20] S. Y. Buckman, A. Gresham, P. Hale et al., "COX-2 expression is induced by UVB exposure in human skin: implications for the development of skin cancer," Carcinogenesis, vol. 19, no. 5, pp. 723-729, 1998.

[21] T. M. Chiu, C. C. Huang, T. J. Lin, J. Y. Fang, N. L. $\mathrm{Wu}$, and C. F. Hung, "In vitro and in vivo anti-photoaging effects of an isoflavone extract from soybean cake," Journal of Ethnopharmacology, vol. 126, no. 1, pp. 108-113, 2009.

[22] J. O. Moore, Y. Wang, W. G. Stebbins et al., "Photoprotective effect of isoflavone genistein on ultraviolet B-induced pyrimidine dimer formation and PCNA expression in human reconstituted skin and its implications in dermatology and prevention of cutaneous carcinogenesis," Carcinogenesis, vol. 27, no. 8, pp. 1627-1635, 2006. 

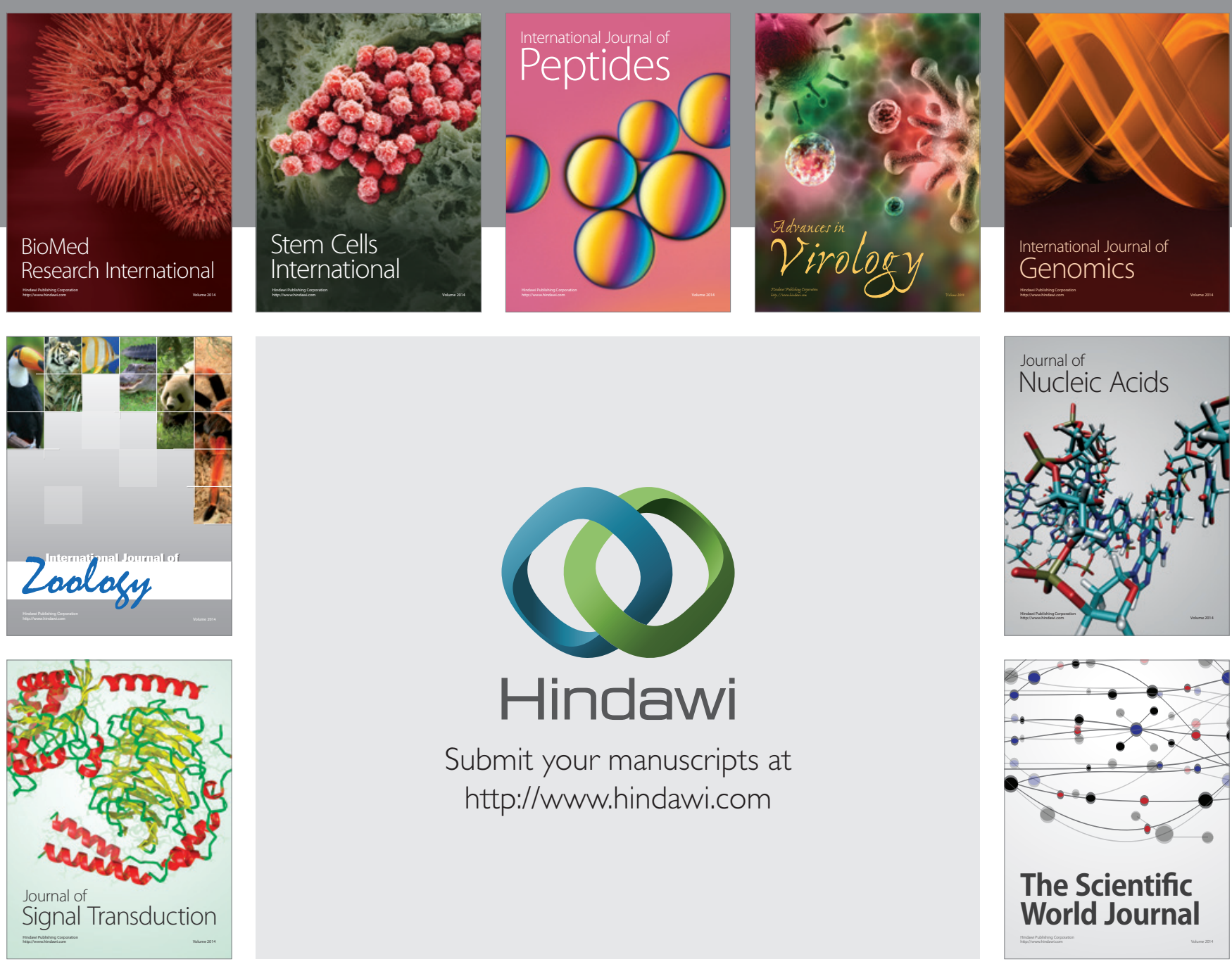

Submit your manuscripts at

http://www.hindawi.com
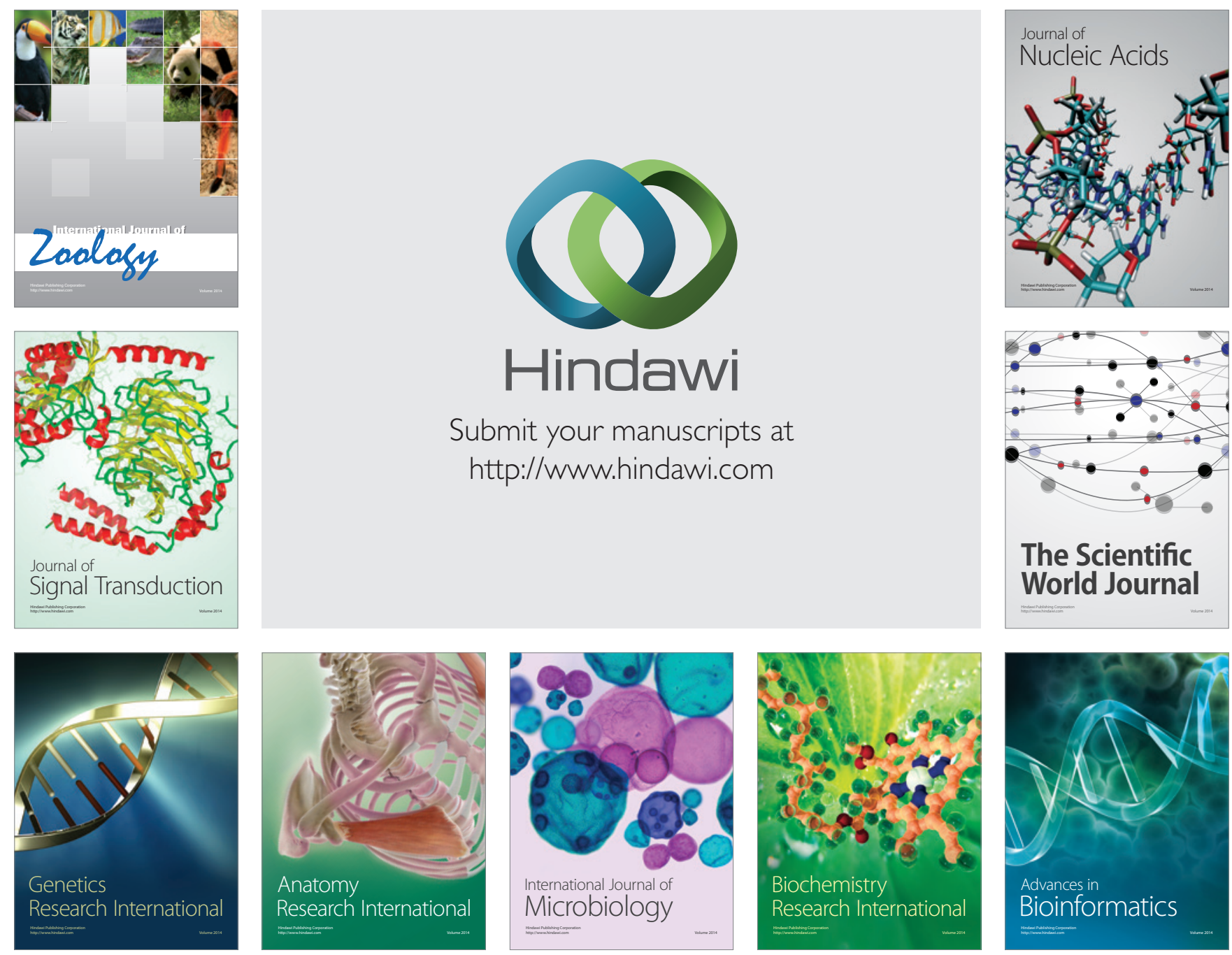

The Scientific World Journal
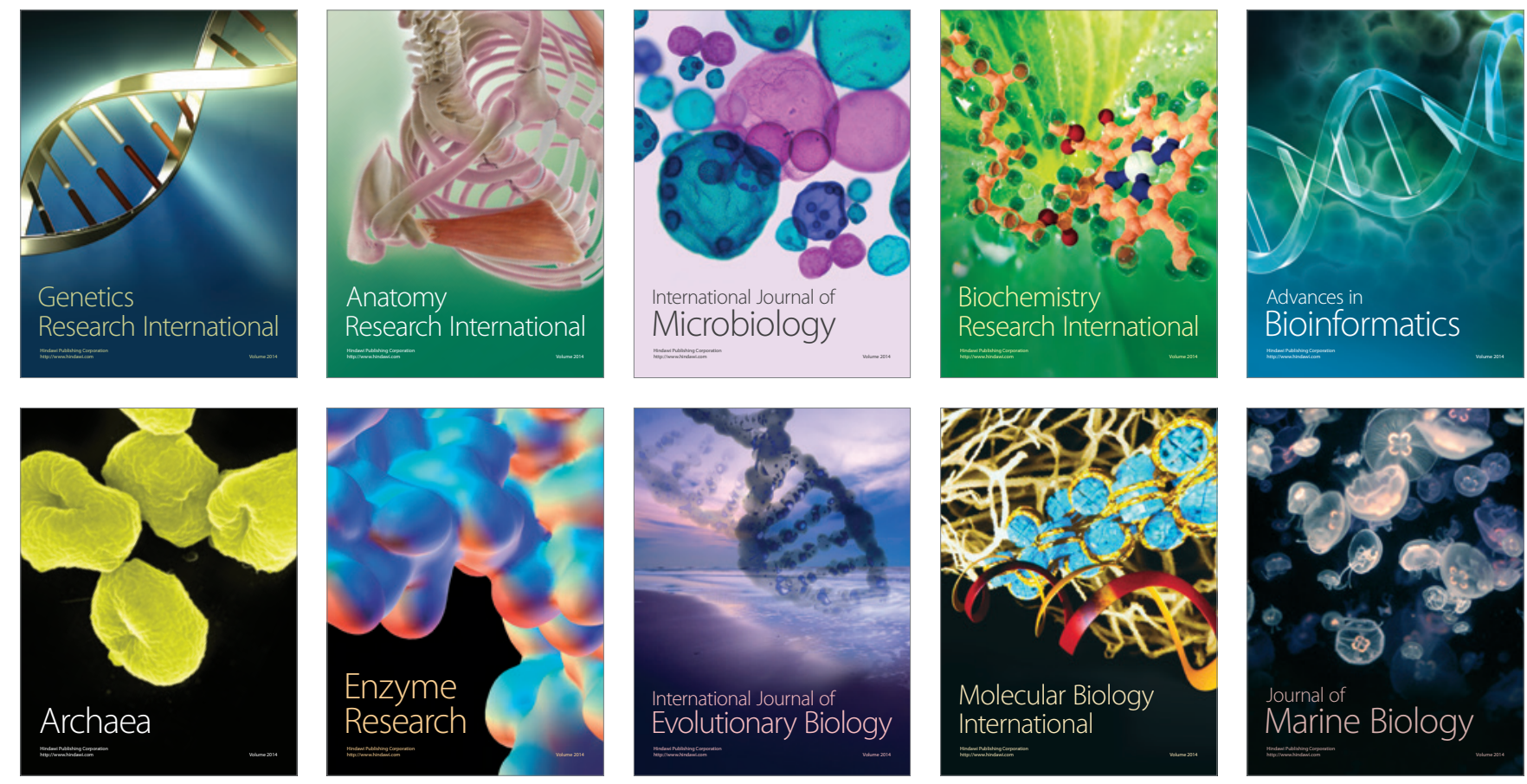